\title{
AVALIAÇÃO DOS PROCESSOS COMBINADOS DE EXTRUSÃO E AGLOMERAÇÃO NA SOLUBILIDADE DE HIDROCOLOIDES
}

\section{Maria Eugênia Araújo Silva Oliveira ${ }^{1}$; Pedro Pio Campregher Augusto ${ }^{2}$; Fernanda Zaratini Vissotto $^{2}$; Carlos Wanderlei Piler de Carvalho ${ }^{3}$; Renata Galhardo Borguini ${ }^{3}$; Cristina Yoshie Takeiti ${ }^{1,3}$}

1-Programa de Pós-Graduação em Alimentos e Nutrição (PPGAN), Universidade Federal do Estado do Rio de Janeiro (UNIRIO), Rio de Janeiro-RJ, Brasil (meuginia@gmail.com)

2-Instituto de Tecnologia de Alimentos (ITAL), Campinas-SP, Brasil

3-Empresa Brasileira de Pesquisa Agropecuária (EMBRAPA), Rio de Janeiro - RJ, Brasil

A goma carragena é um hidrocoloide de origem marinha. A goma arábica é um exsudato extraído de árvores africanas do gênero Acacia. A extrusão termoplástica combina calor, cisalhamento e umidade aplicados em um curto período de tempo e a aglomeração é uma técnica que modifica a estrutura física de produtos em pós. O objetivo do trabalho foi avaliar as propriedades físicas dessas gomas após os processamentos. As gomas foram adquiridas comercialmente. A extrusão foi realizada em extrusora dupla rosca com as seguintes condições: $400 \mathrm{rpm}$ de rotação dos parafusos, $1 \mathrm{~L} / \mathrm{h}$ vazão de líquidos, $3,5 \mathrm{~kg} / \mathrm{h}$ de vazão de sólidos e temperaturas das zonas de aquecimento compreendidas entre 40 e $120{ }^{\circ} \mathrm{C}$ para goma carragena e $400 \mathrm{rpm}$ de rotação dos parafusos, $3 \mathrm{~L} / \mathrm{h}$ vazão de líquidos, $3,5 \mathrm{~kg}$ de vazão de sólidos e temperaturas das zonas de aquecimento da extrusora compreendidas entre 40 e $90{ }^{\circ} \mathrm{C}$ para goma arábica. Após a extrusão as amostras foram secas em estufa e segregadas em três tamanhos de partículas $(212 \mu \mathrm{m}, 106 \mu \mathrm{m}$ e fundo). A algomeração foi realizada nas seguintes condições: 1,2 bar de vapor saturado, $550 \mathrm{~g} / \mathrm{min}$ de alimentação e secagem dos pós com fluxo de ar quente à $70^{\circ} \mathrm{C}$ nas amostras com tamanho de partícula $106 \mu \mathrm{m}$ para goma carragena e partículas "fundo" para a goma arábica, por terem sido produzidas em maior proporção após extrusão. Foram feitos testes de dissolução, densidade aparente, umidade e atividade de água. Quanto ao material não extrudado, goma arábica apresentou aspecto de material aglomerado, diferentemente da goma carragena. A goma arábica aglomerada e a goma arábica extrudada e aglomerada dissolveram-se instantaneamente ( $2 \mathrm{~s})$. Entretanto, a goma carragena extrudada e aglomerada apresentou considerável diminuição no tempo de dissolução (1800 s) em relação à goma não extrudada (7200 s) e à goma extrudada fração $106 \mu \mathrm{m}$ (3924 s). O maior valor de densidade aparente $(0,7 \mathrm{~g} / \mathrm{mL})$ foi para a goma arábica não extrudada. Todas as amostras apresentaram umidade abaixo de $15 \%$ e atividade de água abaixo de 0,4. Os resultados indicam que o efeito combinado da extrusão com aglomeração melhorou as características de dissolução de ambas as gomas, sendo mais evidenciado na goma arábica, possibilitando sua utilização em produtos à base de fibra alimentar. 